\title{
Health Inequalities and Ethnic Vulnerabilities During COVID-19 in the UK: A Reflection on the PHE Reports
}

\section{Clare Keys $^{1} \cdot$ Gowri Nanayakkara $^{2}$ D Chisa Onyejekwe ${ }^{2} \cdot$ Rajeeb Kumar Sah $^{3}$. Toni Wright ${ }^{3}$}

Accepted: 11 November 2020 / Published online: 14 January 2021

(c) Springer Nature B.V. 2021

\begin{abstract}
COVID-19 has uncovered the vulnerabilities, inequalities and fragility present within our social community which has exposed and exacerbated the pre-existing racial and socioeconomic inequalities that disproportionately affect health outcomes for Black, Asian and Minority Ethnic (BAME) people. Such disparities are fuelled by complex socioeconomic health determinants and longstanding structural inequalities. This paper aims to explore the inequalities and vulnerabilities of BAME communities laid bare by the Public Health England (PHE) reports published in June 2020, concluding with suggested strategies to address inequalities in a post COVID19 recovery.
\end{abstract}

Keywords BAME $\cdot$ COVID-19 $\cdot$ Vulnerabilities $\cdot$ Inequalities $\cdot$ Intersectionality

Gowri Nanayakkara

gowri.nanayakkara@canterbury.ac.uk

Clare Keys

clare.keys1@canterbury.ac.uk

Chisa Onyejekwe

chisa.onyejekwe@ canterbury.ac.uk

Rajeeb Kumar Sah

rajeeb.sah@canterbury.ac.uk

Toni Wright

toni.wright@canterbury.ac.uk

1 Faculty of Education, Canterbury Christ Church University, Kent, UK

2 Faculty of Science, Engineering and Social Sciences, Canterbury Christ Church University, Kent, UK

3 Faculty of Medicine, Health and Social Care, Canterbury Christ Church University, Kent, UK 


\section{Introduction}

The COVID-19 pandemic has turned out to be the most significant challenge humankind has faced since the Second World War. In Europe, the United Kingdom (UK) is one of the worst affected countries both in terms of total numbers of illness and deaths due to COVID-19 (JHU 2020). In March 2020, when some highprofile people in the UK, including Boris Johnson, ${ }^{1}$ Matt Hancock, ${ }^{2}$ Chris Witty ${ }^{3}$ and Prince Charles tested positive for coronavirus, we were told 'we are all in this together, coronavirus does not discriminate'-but, are we really in this together? Almost every COVID-19 analysis has confirmed that older people, people living with comorbidities, those from deprived communities and minority ethnic groups are disproportionately affected by severe illness and deaths due to COVID-19. The Office for National Statistics (ONS) (2020a) has reported that COVID-19 mortality rates are highest among people from BAME groups, with Black males 3.3 times more likely to die compared to their white counterparts.

The impact of COVID-19 on minority ethnic populations is complex and integrated, ranging from the geographical area, living conditions and employment to biological factors - although such factors do not act independently (Elwell-Sutton et al. 2020). A survey by the Runneymede Trust has unequivocally reported that COVID-19 is not just a health crisis; it is also a social and economic crisis (Haque et al. 2020). The real impact of COVID-19 is wide-ranging, and evidence is still evolving, especially for people from BAME and socioeconomically deprived communities. ${ }^{4}$ COVID-19 has uncovered the vulnerabilities and fragility present within society that has exposed and exacerbated pre-existing racial and socioeconomic inequalities to disproportionately affect health outcomes for BAME people (Crenshaw 2020a). This disparity is fuelled by complex socioeconomic health determinants and longstanding structural inequalities (Marmot et al. 2020).

The continuous reproduction of racial inequalities can be seen through lack of resources due to historical racism, poverty, social deprivation, ethnic and health vulnerabilities that COVID-19 has laid bare. Thus, this paper, in light of the PHE reports published in June 2020 (PHE 2020a, b) aims to explore the inequalities and vulnerabilities for BAME communities. It draws on feminist intersectional insights to deepen understanding and suggests an ethics of care strategy to address inequalities as the pandemic unfolds in the UK.

\footnotetext{
1 The incumbent Prime Minister of the UK.

2 The Health Secretary (UK).

3 The Chief Medical Officer (UK).

4 A recent example is from the chaos created by the unfair A-level results where young people from disadvantaged and BAME backgrounds in the UK had their grades disproportionately downgraded (Coughlan et al. 2020). The U-turn from the Government over the A-level results was a relief but it also caused distress for many young people. This has potential effects for the rest of their lives.
} 


\section{PHE Reports}

The COVID-19 reports published by Public Health England ${ }^{5}$ (PHE 2020a) in June 2020 were meant to investigate the reasons behind the unequal fatalities of members of BAME communities. The reports unsurprisingly became a magnifying glass that accentuated the inequalities and intersectional violence Black and Brown bodies encounter currently, as well as historically (Crenshaw 2020a). The reports assert that racism, discrimination and social inequalities may have contributed to the increased risks of acquisition, complications and death from COVID-19 among minority ethnic people. They not only acknowledged that the pandemic had exposed longstanding inequalities affecting BAME communities in the UK but that they were also exacerbated by the conditions under which BAME people live.

The unequal burdens of morbidity and mortality among BAME groups are hardly surprising as historical accounts of influenza pandemics and infectious diseases have clearly shown that poverty and inequalities create favourable conditions for breeding and transmission of infectious diseases (Crenshaw 2020a; Quinn and Kumar 2014). It is well documented that minority ethnic groups have higher rates of poverty compared to the average UK population (Platt 2007). Additionally, there is enough evidence of racism, including institutional racism, experienced by BAME communities in the UK, and this has been recognised by the UK Government (Toleikyte and Salway 2018). Marmot and colleagues (2020) reported that intersections between socioeconomic status, ethnicity and racism intensify health inequalities.

Besides all this evidence, PHE's COVID-19 review has again failed those from minority ethnic backgrounds. The Government has not been able to take into account the historical perspectives adequately and is believed to have not only delayed the publication of this initial review but also suppressed the release of the full report that includes recommendations (Khunti et al. 2020). Medical and race equality organisations were angered and frustrated, as the initial review did not include a single recommendation or produce any plan for protecting BAME people from the disease. Moreover, it was widely reported that an earlier draft of this review included responses from more than 1000 organisations and individuals suggesting discrimination as a contributing factor to the increased risk from COVID-19, however PHE insisted nothing had been removed from the initial report (Iacobucci 2020a). Following a public outcry and heavy criticisms from the British Medical Association (BMA) and other BAME organisations, PHE were compelled to publish the previously withheld recommendations, which acknowledged that racism, discrimination and social inequality may have contributed to the increased risk of death from COVID-19 among BAME communities (lacobucci 2020b). The staggered strategic

\footnotetext{
5 PHE was established on 1 April 2013 as an executive agency of the UK Department of Health and Social Care, with an operational autonomy, to protect and improve the nation's health and wellbeing and reduce health inequalities. PHE is responsible for preparing, planning and responding to public health emergencies and health protection concerns such as the current COVID-19 pandemic. PHE provides evidence-based professional, scientific and delivery expertise and advice to the Government, local authorities, NHS and public health professionals. PHE is to be replaced by the National Institute for Health Protection from spring 2021.
} 
release of these reports portrayed the plight of BAME communities in a different light. The first report while admitting the unequal rate of COVID-19 impact on BAME communities, also identified apparent health deficiencies mostly related to Black and Brown bodies as an explanation for such differences. The reports' identification of certain health conditions that made Black and Brown bodies more susceptible to COVID-19 as opposed to white bodies exacerbated the situation for BAME communities, thus making them a highly vulnerable group to COVID-19 from a health as well as from a social perspective.

These PHE reports reinforce the Western understanding of health as the absence of any medically recognised diseases/conditions (Herring 2016). Such an ableist approach painted Black and Brown bodies with underlying health conditions such as diabetes mellitus, cardiovascular disease and hypertension as deficits and a weakness in containing, battling and curing COVID-19. The report highlighting the health deficiencies of Black and Brown bodies frames them as bodies that 'lack', and does the work of concealing the historical racial violence that cause conditions for ill health. Such 'curative violence' (Kim 2017) serves to subject Black and Brown bodies to more violence under this COVID-19 moment as they are considered an undue burden on the National Health Service (Uthayakumar-Cumarasamy 2020).

Although communities and stakeholders welcomed the second PHE report, it raised questions about the mixed messages surrounding its publication and lack of transparency that has eroded trust within BAME communities (lacobucci 2020b). If not for the subsequent report, which curated the lived experiences of structural violence encountered by the stakeholders, i.e. BAME representatives, a holistic picture of the situation would not have been revealed. Research into health inequalities has predominantly homogenised BAME communities, boxing them into a 'one size fits all' category. The stakeholders involved in providing recommendations in the second report highlighted that the intersections between racism, social inequality and the pandemic have exacerbated pre-existing structural inequalities which have affected BAME communities disproportionately, making them more vulnerable to morbidity and mortality from COVID-19.

The following sections highlight inequalities exacerbated by the impact of COVID-19 and offer some intersectional consideration to develop that understanding. They also provide some strategies to address the inequities beyond COVID-19 in the UK.

\section{Intersectionality-Unmasking Race and Racism}

Intersectionality was lexiconised by feminist legal scholar and activist Crenshaw $(1989,1991)$ some thirty years ago as a tool for analysing the gendered racism experienced by Black women. The term is a metaphor for a complex set of crossroads (intersections) where axes of power meet; highlighting oppressions as multiple and interconnected (Yuval-Davis 2006). The concept comes from a long tradition of Black feminist thought and activism, from Anna Julia Cooper and Sojourner Truth in the mid and late 19th Century to the Combahee River Collective in the late 20th century and beyond, focused on the lived experience and material realities of Black 
women (Cooper 2017; Crenshaw 2017; Taylor 2017). An intersectional framework for analysis is vital in this COVID-19 moment as it teaches us a lot about enduring multiple and mutually constitutive health and social inequalities related to race, class, age, gender and disability (Collins and Bilge 2016).

Unmasking racism in healthcare would require a retelling of the political context and historic violence Black and Brown bodies suffered from colonialisation to the neo-colonial era of today, where the opportunistic extraction of human labour is prioritised with no accountability for safeguarding lives, living conditions, dignity and health (Tyler 2020). The complex and violent relationship the UK has with Black and Brown bodies is starkly visible throughout history where they were enslaved, colonised and indentured constructors of the UK economy, commonwealth subjects as British nationals (British Nationality Act 1948), migrants (Commonwealth Immigrants Act 1962) and illegal aliens (Windrush generation and forced migrations). However, when they were subjected to racism and discrimination, the UK was lethargic in its efforts to find reparations for 'used' Black and Brown bodies. The inability to enact a race discrimination bill from the 1940s until late 1960s (the Bill was defeated nine times by Parliament) is evidence of historic delays in protecting and providing equity to BAME communities. The 1965 Race Relations Act only managed to make racial discrimination illegal in public places, but not in shops or private housing. More recently delayed protection and inequity was uncovered by the Windrush scandal. These are examples that demonstrate the lack of value given to Black and Brown bodies. Reni Eddo-Lodge states, "Britain created a global empire it could draw labour from at ease. But wasn't ready for repercussions and responsibilities that came with its colonising countries and cultures. It was Black and Brown people who suffered the consequences" (Eddo-Lodge 2018,15).

When looking at the implications of COVID-19 on minority ethnicities, the 'Race for Equality' document, highlights that health inequalities tend to be focused on the socioeconomic impact of ill-health with little space for looking at race inequalities separately or entwined with socioeconomic factors. This lack of attention to racial inequality and intersections of need is predominant in NHS focused initiatives (Salway et al. 2014). This has ultimately led to simple and disconnected strategies of support being implemented; ineffective for sustained improvement of care at both local and national levels of policy making and caregiving. The second PHE report acknowledged that solutions to barriers around access to health prevention and care will be complex and must be culturally competent and sustainable to be effective. This paper identifies intersectional inequalities BAME people experience that contribute towards COVID-19 high mortality. The paper also makes suggestions for an ethics of care approach towards health equity for all communities.

\section{Socioeconomic Inequalities}

The disproportionately high number of BAME deaths from COVID-19 revealed that people from BAME communities are more likely to live in deprived areas (PHE 2020b) and work in low-paid and insecure work (TUC 2016), and that a disproportionate number of those also engaged in work in the health economy are women of 
colour (Crenshaw 2020b). Racism plays a significant role due to a lack of access to higher paid, more secure, employment opportunities for working class BAME workers living in deprived neighbourhoods. Living in deprived neighbourhoods often means living in overcrowded and densely populated housing (Tyler 2020), meaning people more often in contact with each other, negatively impacting on health outcomes by increasing the risk of contracting COVID-19. Additionally, living in such neighbourhoods limits job opportunities. Research suggests that postcode discrimination exists and is part of the explanation for higher unemployment in deprived areas. Working class BAME communities are affected by this strategy used by employers as they disproportionately live in under-developed areas and are discriminated against based on their postcode (Nunn et al. 2010).

BAME workers in the UK are more likely to be on temporary, fixed-term or zerohours contracts compared to white workers (TUC 2016b). This has a knock-on effect on earnings since workers on precarious contracts earn significantly less on average than workers on permanent contracts. In 2019, white household income, on average, was about $65 \%$ higher compared to Black households (ONS 2020b). Similarly, average savings amongst BAME populations are much less than their white counterparts: for every $£ 1$ of white British wealth, Pakistani households have around 50p, Black Caribbean households around 20p, and Black African and Bangladeshi households approximately 10p (Khan 2020).

The forms of raced classism resulting in deprivation and disadvantage have a long lineage in the UK. Consequently, BAME people, especially those from working class backgrounds, are at an increased risk of exposure to COVID-19 in their workplace through overcrowded and multigenerational living arrangements. Densely populated multigenerational households mean that social distancing, self-isolation and shielding are harder to practise, increasing opportunities for within household coronavirus transmission.

A neo-liberal creeping conservatism that has manifested as an unrelenting attack on the most vulnerable in society has been taking place for over 40 years. COVID-19 has merely uncovered the conditions brought forth as a result of living for decades under late capitalism's disregard for bodies that are viewed as economically unproductive (Crenshaw 2020c). These dynamics have been intensified by more recent shifts in the organisation and nature of work termed precaritisation (Bhattacharya 2018; Tyler 2020). Bhattacharya posits that this term is not only applied to workers providing essential 'social reproductive' services such as health and social care but across a range of other sectors and industries, including food processing, retail and distribution. COVID-19 political discourse recharacterise these jobs as 'key worker' roles. These sectors comprise some of the most low-paid and precarious workers in the UK economy, especially in cleaning, childcare, retail and social care; sectors predominantly employing women (Crenshaw 2020b). The interconnected class, gender and racial dimensions of precarity are therefore critical to understanding the implications of COVID-19 for different types and locations of work. 


\section{Health Inequalities}

The current pandemic highlights disparities regarding the illness and death of those from BAME communities. However, these inequalities in health and healthcare provision for BAME communities are well-established. BAME populations are at higher risk of mental and physical illness in the UK (Mentalhealth.org 2019) to a lesser or greater degree depending on positionality and the intersections of race and gender, class, age and disability. The National Institute for Health and Care Excellence (NICE) quality standards (2018) state that the key to developing a strong voice for BAME communities relating to physical and mental wellbeing is the local community.

In England and Wales, nearly 20\% of the total population are from BAME backgrounds (MentalHealth.org 2019). Mirroring this, a fifth of the total NHS workforce are from BAME backgrounds (Issar 2019); including pharmacists doubles the figure to $40 \%$ (Patel 2020). Therefore, in theory, BAME representation is present in the healthcare workforce. The issue, however, is that this representation is not at levels of leadership and management, or visible in all communities, especially rural areas; thus, adding to prevalent continuing discrimination and healthcare failings. Further, intersectional understandings of representation are lacking. There is emphasis on representation by race, but little is known about how race intersects with gender, class, age and disability, although the precarity of work for women of colour in the low wage health and social care economy is known (Crenshaw 2020b).

Cultural awareness and community outreach by healthcare providers, encouraging links with community elders and spiritual leaders could reduce feelings of discrimination and isolation for those most at risk of health inequalities. This is at no time more critical than throughout the monitoring of COVID-19 infections countrywide. The BMA (2020) state that steps must be urgently implemented to protect BAME populations whilst higher accuracy levels of data are gathered on COVID-19 infection rates and deaths in hospitals. A greater understanding of risks, prevention strategies and symptoms requiring healthcare support can be facilitated by community leaders through cultural events and by spiritual leaders through their communications with worshipers. Key health messages could also be shared through BAME media sites and social media influencers (Patel 2020). The UK has a poor track record on engaging in genuine community-led healthcare initiatives where it is the community leaders who suggest ways to progress new ways of working. However, successes globally can be seen in taking this approach.

Rose et al. (2020) argue that health inequalities in the UK were increasing in the decade before the COVID-19 pandemic and that in order to have the most significant impact on reducing inequalities, resources need to be delivered in proportion to the degree of need. They argue that current approaches are not sufficiently considering the critical drivers of need tied to poverty, race and ethnicity. The centralised 
and universal implementation of control measures that has been applied so far will not address these inequalities.

Black Lives Matter is one example of an intersectional queer women of colour founded and led movement that drives community engagement for social impact and transformation (Khan-Cullors and Bandele 2018). Such a method could support knowledge and action to change the materialities of life for marginalised peoples through policy development and implementation, as well as social and cultural change. A more bottom-up community-led race critical approach to healthcare that recognises the mutually constitutive subjectivities of gender, class, age and disability is likely to better attend to the needs of all stakeholders.

\section{Ethics of Care}

An intersectional analysis of the impact of COVID-19 is essential to develop an effective new way of working, as layers of identity add complexity to individual experiences of discrimination or vulnerability (Crenshaw 2017). However, going forward, connections between unacceptable experience of patients and imperfect practice of healthcare providers are critical and can be recognised through a process of intra-sectionality (Katri 2017; Gunnarsson 2017; Lykke 2010; Barad 2007). The notion that there should be an entwined and mutual journey by relevant agencies towards new thinking, as opposed to a reworking of detached agencies rubbing alongside each other, could be revolutionary in addressing complex vulnerabilities heightened by the COVID-19 pandemic.

The aim must surely now be to have a proactive, rather than reactive healthcare system-more collaborative than fragmented (Bengoa 2019). In short, the UK requires connections between groups providing and receiving healthcare, this could be through embracing an intra, self-reflexive perspective to care provision or employing the proposed 'bottom-up' approach to healthcare initiatives "whereby the deliverers of public services are accountable primarily to the communities they serve" (Awio et al. 2007, 210). This means allowing the needs of communities to drive the approach rather than leadership or management by healthcare providers who often do not respond well to the needs of specific populations. A culture of interdependency between providers and community would create greater awareness on both sides of the challenges faced by those most marginalised within society. This leads to greater empathy, encouraging increased focus on ethics of care, thus recognising the connectedness of responsive care and recognition of systematic marginalisation (Brannelly 2015). This change in direction towards increased cohesiveness between provider and patient should also lead towards less stigmatisation and such a method could create the intra-sectional awareness required to reduce vulnerabilities for BAME populations and reduce or remove the distal and proximal stressors interrupting positive healthcare experiences, thus improving both physical and mental health.

This basic need of respect and care ethics, whether as a patient or healthcare professional, is a fundamental requirement for enabling systematic change. Ethics of 
care is grounded within the acceptance of vulnerability in self and others. Indeed, if we consider vulnerability an essential feature of 'being human' (Duncan 2009) and 'to care' as an acceptance that people matter (Brechin et al. 1998) it brings with it a moral responsibility to ensure individuals are cared for with equity of outcomes. Ultimately a cultural understanding of patients and their care needs accelerates the empathetic foundations that lead to real change in practice. A care ethics approach, championing empathy, could also allow greater understanding to emerge around institutional racism in healthcare experienced by both staff and service users, addressing systemic and intrasectional inequalities in healthcare provision and outcomes (Kline et al. 2017). As Slote notes, "A care ethics that takes empathy seriously and uses the notion systematically can say what is wrong with patriarchal ideas and institutions in a highly persuasive and forward-looking way" (Slote 2007 xiii).

It is comprehensive awareness of lived experiences that allows for inequalities to be understood and it is this grassroots understanding of responsibility that allows forward looking, action focused practice (Brannelly 2015). Therefore, the allyship between provider and community must become more visible.

\section{Conclusion}

The COVID-19 pandemic has reinforced the need to deal with the challenges posed by racism and inequalities that have disproportionately impacted on BAME people in the crisis in complex ways, according to mutually influencing intersections of gender, class, age and disability. We could expect that the most negatively affected play a central role in initiating and leading the response activities. However, the criticism that the UK's national research funding has not awarded any of its recent grants on COVID-19 research to Black principal investigators (Inge 2020) raises serious concerns about the engagement of BAME academics, researchers and research participants in understanding the full picture of the impact of the pandemic and the development of strategies in a post-COVID world. Jayshree Pillaye, a retired general practitioner and public health doctor writes,

The question is whether the plethora of publications and media reports on the disproportionate effect of COVID-19 on BAME communities will decrease the burden of infection and deaths in any subsequent pandemic. Or will they languish as previous reports until resurrected with the next health emergency? A repeated narrative composed of "cut and paste" and reframing of deprivation and racism as the cause of or way forward in tackling the poor health outcomes in BAME groups is often used as a defence and distraction from proactive and timely intervention. (Pillaye 2020,1)

In order to prevent distracting from the issue at hand, this paper lobbies for taking into account the wide-ranging and intersectional lived experiences of people from BAME communities, facilitating a diverse set of BAME academics' and researchers' input in introducing policy changes, and the extensive involvement of the community and spiritual leaders in sharing knowledge and information through a 
bottom-up approach as crucial methods in forging meaningful measures to mitigate the health inequalities encountered by BAME people. Appropriate intersectional and intra-sectional approaches need to be utilised when identifying health inequalities faced by BAME communities, while a care ethics approach needs to be considered when addressing such inequalities.

\section{References}

Awio, Godwin, Stewart Lawrence, and Deryl Northcott. 2007. Community-led initiatives: reforms for better accountability? Journal of Accounting and Organizational Change 3 (3): 209-226.

Barad, Karen. 2007. Meeting the Universe halfway: Quantum physics and the entanglement of matter and meaning. Durham: Duke University Press.

Barnard, Helen, and Claire Turner. 2011. Poverty and ethnicity: A review of evidence. York: Joseph Rowntree Foundation.

Bengoa, Rafael. 2013. Transforming health care: an approach to system-wide implementation. International journal of integrated care. https://doi.org/10.5334/ijic.1206.

Bhattacharyya, Gargi. 2018. Rethinking racial capitalism: Questions of reproduction and survival. London: Rowman and Littlefield.

Brannelly, Tula. 2015. Mental health service use and the ethics of care: In pursuit of justice. In Ethics of Care: critical advances in international perspective, ed. Marian Barnes, Tula Brannelly, Lizzie Ward and Nicki Ward, 219-232. Bristol: Policy Press.

Brechin, Ann. 1998. Introduction. In Care matters concepts, practice and research in health and social care, ed. Jan Walmsley, Jeanne Katz, and Sheila Peace, 1. London: Sage.

British Medical Association (BMA). 2020. BMA Media Team Review into COVID-19 impact on BAME communities must be backed by real-time data and include measures to address problem now, says BMA. https://www.bma.org.uk/bma-media-centre/review-into-covid-19-impact-onbame-communities-must-be-backed-by-real-time-data-and-include-measures-to-address-probl em-now-says-bma Accessed 18 July 2020.

Cooper, Anna Julia. Scrapbook no. 2, 1931-1940. Anna Julia Cooper Collection. Washington, DC: Howard University.

Coughlan, Sean, Sellgren, Katherine and Burns, Judith. 2020. A-levels: Anger over 'unfair' results this year. $B B C, 13$ August. https://www.bbc.co.uk/news/education-53759832\#: :text=There $\% 20$ is $\% 20$ anger\%20among $\% 20$ schools,were\%20lower\%20than\%20teachers $\% 27 \% 20$ predicti ons.\&text=The $\% 20$ overall $\% 20$ results $\% 2 \mathrm{C} \% 20$ across $\% 20$ England,for $\% 20 \mathrm{~A} * \% 20$ and $\% 20 \mathrm{~A} \% 20$ grades. Accessed 20 Aug 2020.

Crenshaw, Kimberle. 1989. Demarginalizing the intersection of race and sex: A Black feminist critique of antidiscrimination doctrine, feminist theory and antiracist politics. University of Chicago Legal Forum 1 (8): 139-167.

Crenshaw, Kimberle. 1991. Mapping the margins: intersectionality, identity politics and violence against women of color. Stanford Law Review 43 (6): 1241-1299.

Crenshaw, Kimberle. 2017. On intersectionality: Essential Writings. New York: New Press.

Crenshaw, Kimberle. 2020a. Intersectionality matters: under the blacklight: history rinsed and repeated [Podcast]. 28 April 2020. https://soundcloud.com/intersectionality-matters/14-under -the-blacklight-history-rinsed-and-repeated. Accessed 20 Aug 2020.

Crenshaw, Kimberle. 2020b. Intersectionality matters: under the blacklight: COVID in confinement [Podcast]. 5 May 2020. https://soundcloud.com/intersectionality-matters/15-pt-6-under-the-black light-covid-in-confinement. Accessed 20 Aug 2020.

Crenshaw, Kimberle. 2020c. Intersectionality matters: under the blacklight: COVID and disaster white supremacy [Podcast]. 21 April 2020. https://soundcloud.com/intersectionality-matte rs/13pt-4-under-the-blacklight. Accessed 20 Aug 2020.

Duncan, Peter. 2009. Values, Ethics and Healthcare. London: Sage.

Eddo-Lodge, Reni. 2018. Why I'm no longer talking to white people about race. London: Bloomsbury Publishing. 
Elwell-Sutton, Tim, Deeny, Sarah, and Stafford, Mai. 2020. Emerging findings on the impact of COVID-19 on black and minority ethnic people. https://www.health.org.uk/news-and-comme nt/charts-and-infographics/emerging-findings-on-the-impact-of-covid-19-on-black-and-min Accessed 21 July 2020.

Fineman, Martha Alberston. 2015. Equality and Difference-The Restrained State. Emory Legal Studies Research Paper No 15: 348-367.

Gunnarsson, Lena. 2017. Why we keep separating the 'inseparable': Dialecticizing intersectionality. European Journal of Women's Studies 24 (2): 114-127.

Haque, Zubaida, Laia Becares, and Nick Treloar. 2020. Over-exposed and under-protected: the devastating impact of COVID-19 on black and minority ethnic communities in Great Britain. London: The Runnymede Trust.

Herring, Jonathan. 2016. Health as vulnerability; interdependence and relationality. The New Bioethics 22 (1): 18-32.

Hill, Collins Patricia, and Bilge Sirma. 2016. Intersectionality. Cambridge: Polity Press.

Hudson, Darrell L., Eli Puterman, Kirsten Bibbins-Domingo, Karen A. Matthews, and Nancy E. Adler. 2013. Race, life course socioeconomic position, racial discrimination, depressive symptoms and self-rated health. Social Science and Medicine 97: 7-14.

Iacobucci, Gareth. 2020. Covid-19: PHE review has failed ethnic minorities, leaders tell BMJ. BMJ 369: $\mathrm{m} 2264$.

Iacobucci, Gareth. 2020. Covid-19: Racism may be linked to ethnic minorities' raised death risk, says PHE. BMJ 369: m2421.

Inge, Sophie. 2020. UKRI in row over absence of black PIs in its Covid-19 BAME grant. 7 August. https://www.researchprofessionalnews.com/rr-news-uk-research-councils-2020-8-ukri-in-rowover-absence-of-black-pis-in-its-covid-19-bame-grant/ Accessed 10 August 2020.

Issar, Prerana. 2019. A Fair Experience for All; Closing the ethnicity gap in rates of disciplinary action across the NHS workforce. London: WRES Implementation Team, NHS.

John Hopkins University (JHU). 2020. Global Map. https://coronavirus.jhu.edu/map.html Accessed 10 August 2020.

Katri, Ido. 2017. Transgender Intrasectionality: Rethinking Anti-discrimination Law And Litigation. University of Pennsylvania Journal of Law and Social Change. 20 (1): 51-79.

Khan, Omar. 2020. The colour of money: how racial inequalities obstruct a fair and resilient economy. London: The Runnymede Trust.

Khan-Cullors, Patrisse, and Asha Bandele. 2018. When they call you a terrorist: a black lives matter memoir. New York: St. Martin's Griffin.

Khunti, Kamlesh, Lucinda Platt, Ash Routen, and Kamran Abbasi. 2020. Covid-19 and ethnic minorities: an urgent agenda for overdue action. BMJ 369: m1548.

Kim, Eunjung. 2017. Curative violence: Rehabilitating disability, gender, and sexuality in modern Korea. USA: Duke University Press.

Kline, Roger, Habib Naqvi, Razaq, Saba A, and Wilhelm, Reg. 2017. NHS Workforce Race Equality Standard. 2016 Data Analysis Report for NHS Trusts.

Lyfar-Cisse, Vivienne. 2017. NHS Workforce Race Equality Standard (WRES): Report and Action Plan. WRES: Brighton and Sussex University NHS Trust.

Lykke, Nina. 2010. Feminist Studies: a guide to Intersectional theory, methodology and writing. London: Routledge.

Marmot, Michael, Jessica Allen, Tammy Boyce, Peter Goldblatt, and Joana Morrison. 2020. Health equity in England: The Marmot Review 10 years on. London: Institute of Health Equity.

MentalHealth.org.UK. 2019. Black, Asian and Minority Ethnic (BAME) communities. https://www. mentalhealth.org.uk/a-to-z/b/black-asian-and-minority-ethnic-bame-communities Accessed 18 July 2020.

Naqvi, Haqvi. 2019. Race Equality in the Workplace: A review of Theory and Practice commissioned by the Mary Seacole Trust. https://www.maryseacoletrust.org.uk/wp-content/uploads/2019/02/ Race-Equality-in-the-Workplace-for-publication-Feb-19.pdf Accessed 10 August 2020.

National Institute for Health and Care Excellence (NICE). 2018. Promoting health and preventing premature mortality in black, Asian and other minority ethnic groups. Quality standard [QS167] 11 May https://www.nice.org.uk/guidance/qs167 Accessed 18 July 2020

Nunn, Alex, Bickerstaffe, Time, Hogarth, Terence, Bosworth, Derek, Green, Anne E., and Owen, David. 2010. Postcode selection? Employers' use of area and address-based information shortcuts in recruitment decisions. Department for Work and Pensions. 
Office for National Statistics (ONS). 2020a. Coronavirus (COVID-19) related deaths by ethnic group, England and Wales: 2 March 2020 to 15 May 2020. https://www.ons.gov.uk/peoplepopulationandc ommunity/birthsdeathsandmarriages/deaths/articles/coronaviruscovid19relateddeathsbyethnicg roupenglandandwales/2march2020to15may2020 Accessed 10 August 2020

ONS. 2020b. Effects of taxes and benefits on UK household income: financial year ending 2019. https://www.ons.gov.uk/peoplepopulationandcommunity/personalandhouseholdfinances/incom eandwealth/bulletins/theeffectsoftaxesandbenefitsonhouseholdincome/financialyearending2019 Accessed 10 August 2020

Patel, Mahendra. 2020. Connecting with BAME communities to improve health. Royal Pharmaceutical Society, 5 June. https://www.rpharms.com/blog/details/Connecting-with-BAME-communitie s-to-improve-health Accessed 18 July 20

Pillaye, Jayshree. 2020. Covid-19 and ethnic minorities: the Public Health England report distracts from proactive and timely intervention. British Medical Journal 370: m3054.

Platt, Lucinda. 2007. Poverty and ethnicity in the UK. Bristol: The Policy Press.

Public Health England (PHE). 2020a. Beyond the data: understanding the impact of covid-19 on BAME groups. https://assets.publishing.service.gov.uk/government/uploads/system/uploads/ attachment_data/file/892376/COVID_stakeholder_engagement_synthesis_beyond_the_data.pdf Accessed 10 August 2020.

Public Health England (PHE). 2020b. Disparities in the risk and outcomes of covid-19. https://asset s.publishing.service.gov.uk/government/uploads/system/uploads/attachment_data/file/892085/ disparities_review.pdf Accessed 10 August 2020.

Quinn, Sandra, C., and Kumar Supriya. 2014. Health inequalities and infectious disease epidemics: a challenge for global health security. Biosecurity and bioterrorism: biodefense strategy, practice, and science. 12 (5): 263-273.

Rose, Tanith C., Kate Mason, Andy Pennington, Philip McHale, David C. Taylor-Robinson, and Ben Barr. 2020. Inequalities in COVID19 mortality related to ethnicity and socioeconomic deprivation. medRxiv. https://doi.org/10.1101/2020.04.25.20079491.

Salway, S, et al. A Race Equality Foundation Briefing Paper March 2014 https://www.better-healt h.org.uk. Accessed 20 Aug 2020.

Slote, Michael. 2007. The Ethics of care and Empathy. New York: Routledge.

Taylor, Edward W. 2017. Transformative learning theory. In Transformative learning meets Bildung: An international exchange, ed. Laros, Anna, Thomas Fuhr, and Edward W. Taylor, 17-29. Rotterdam: Sense.

Toleikyte, Lina, and Sarah Salway. 2018. Local action on health inequalities: understanding and reducing ethnic inequalities in health. London: Public Health England.

Trade Unions Congress (TUC) 2016. Insecure Work and Ethnicity https://www.tuc.org.uk/sites/defau 1t/files/Insecure\%20work\%20and\%20ethnicity_0.pdf. Accessed 20 Aug 2020.

Tyler, Imogen. 2020. Stigma: the machinery of inequality. London: Zed Books.

Uthayakumar-Cumarasamy, Amaran. 2020. The 'hostile environment'and the weaponization of the UK health system Medicine. Conflict and Survival 1: 5.

Yuval-Davis, Nira. 2006. Intersectionality and feminist politics. European Journal of Women's Studies 13 (3): 193-209.

Publisher's Note Springer Nature remains neutral with regard to jurisdictional claims in published maps and institutional affiliations. 